\title{
Histone deacetylation, as opposed to promoter methylation, results in epigenetic BIM silencing and resistance to EGFR TKI in NSCLC
}

\author{
MINGCHUAN ZHAO ${ }^{1,2}$, YISHI ZHANG ${ }^{2,3}$, JIAYU LI $^{1}$, XUEFEI $^{2}{ }^{2}$, NINGNING CHENG $^{2}$, QI WANG ${ }^{2}$, \\ WEIJING CAI ${ }^{2}, \mathrm{CHAO}_{\mathrm{ZHAO}}{ }^{2}$, YAYI HE ${ }^{2}$, JIANHUA CHANG ${ }^{1}$ and CAICUN ZHOU ${ }^{2}$ \\ ${ }^{1}$ Department of Oncology, Fudan University Shanghai Cancer Center, Fudan University School of Medicine, \\ Shanghai 200032; ${ }^{2}$ Department of Oncology, Shanghai Pulmonary Hospital, Tongji University School of Medicine, \\ Shanghai 200433; ${ }^{3}$ Department of Oncology, Shenzhen People's Hospital, Shenzhen, Guangdong 518020, P.R. China
}

Received August 28, 2016; Accepted August 3, 2017

DOI: 10.3892/ol.2017.7411

\begin{abstract}
Drug resistance remains a major challenge in epidermal growth factor receptor-tyrosine kinase inhibitor (EGFR-TKI) therapy. Bcl-2-like protein 11 (BIM), a B-cell lymphoma 2 family pro-apoptotic protein, is a prime target for specific anti-cancer therapeutics. However, the epigenetic regulation of BIM in non-small cell lung cancer (NSCLC) cell lines and patients with NSCLC in association with EGFR-TKI resistance requires investigation. Methylation-specific PCR (MSP), pyrosequencing, and nested quantitative (q)-MSP were conducted to explore the methylation status of BIM in NSCLC cell lines. In addition, the methylation profile of BIM in patients with NSCLC was assessed by nested q-MSP using circulating free DNA. Cell lines, treated with methylation inhibitor 5-Aza-2'-deoxycytidine (AZA) or histone deacetylation inhibitor trichostatin A (TSA) prior to gefitinib treatment, were examined for BIM gene expression and resistance to gefitinib. All cell lines used in the present study presented with hypo-methylated BIM. Treatment with AZA had no effect on BIM RNA expression in PC9 cells or the gefitinib-resistant cell lines PC9/R and PC9/G2, nor did it reverse their resistance to gefitinib. In contrast, TSA treatment produced the opposite result. In the present study, 25 (78.1\%) patients with hypo-methylated $B I M$ and 7 patients $(21.9 \%)$ with partial or hyper-methylated $B I M$ were identified. The clinicopathological data revealed a random hypo-methylated
\end{abstract}

Correspondence to: Dr Caicun Zhou, Department of Oncology, Shanghai Pulmonary Hospital, Tongji University School of Medicine, 507 Zhengmin Road, Shanghai 200433, P.R. China

E-mail: caicunzhoudr@163.com

\section{*Contributed equally}

Key words: epidermal growth factor receptor-tyrosine kinase inhibitors, non-small cell lung cancer, bcl-2-like protein 11, histone deacylation, methylation
$B I M$ distribution amongst patients with NSCLC. In the overall study group and EGFR mutant group, hypo-methylated BIM carriers presented with no significant differences in progression free survival compared with patients with partial or hyper-methylated $B I M$. All cell lines in the present study and the majority of patients with NSCLC carried hypo-methylated $B I M$. Histone deacetylation, as opposed to promoter methylation, may contribute to the epigenetic silencing of BIM and lead to EGFR TKI resistance in NSCLC.

\section{Introduction}

Lung cancer is the leading cause of cancer-associated mortality globally $(1,2)$. The discovery and application of epidermal growth factor receptor (EGFR)-tyrosine kinase inhibitors (TKIs) have proved beneficial to patients with sensitive EGFR mutations compared with chemotherapy (3-5). However, $\sim 10 \%$ of patients with activated EGFR mutations demonstrate primary resistance to EGFR-TKI. Another group of patients with an immediate initial response inevitably developed acquired resistance to TKIs in an average time of $\sim 8$ months $(6,7)$. Although, much is known about acquired resistance, only very few primary resistance cases have been elucidated, which involve de novo T790M mutations and Bcl-2-L11 (BIM) deletion polymorphisms $(6,8,9)$. Thus, further study is still required to gain an improved understanding of EGFR-TKI resistance.

A previous study conducted by our group validated the inferior response to EGFR-TKIs in patients carrying the BIM deletion polymorphism (10). BIM is a pro-apoptotic protein that belongs to the B-cell lymphoma-2 (Bcl-2) family (11). Via the $\mathrm{BH} 3$ domain, BIM activates downstream pro-apoptotic proteins, including Bcl-2 homologous antagonist killer (BAK) and $\mathrm{Bcl}-2$ associated $\mathrm{X}$ protein $(\mathrm{BAX})$ and antagonizes anti-apoptotic proteins, including B-cell lymphoma 2 (Bcl-2). The stimulation of BAK and BAX induces the release of cytochrome $\mathrm{c}$ into the cytoplasm and consequently triggers the caspase cascade. Thus, BIM is involved in the mitochondrial apoptotic pathway (12). In EGFR TKI therapy, BIM is pivotal in apoptosis. The BIM deletion polymorphism impairs 
the expression of BH3-containing BIM isoforms and leads to primary resistance to TKIs $(9,10)$. Epigenetic silencing of $B I M$, including promoter methylation and histone-deacetylation, has also been reported in hematological malignances; including Burkitt's lymphoma, non-Hodgkin lymphoma, chronic myeloid leukemia (12-14) and solid tumors, including renal carcinoma (15).

DNA promoter hyper-methylation and histone deacetylation are two major, closely associated epigenetic regulatory mechanisms. Histone deacetylation enhances the methylation-induced inhibition of transcription, by forming the transcription-inhibitory complex. The capacity of histone deacetylation depends on the number of methylated $\mathrm{CpG}$ islands (16). In cases where the gene promoter region was lacking in methylated $\mathrm{CpGs}$ to inhibit transcription, histone deacetylation acted as the major inhibitor in the transcription process. Conversely, methylated CpGs increased the activity of histone deacetylase (HDAC), which further contracted the chromatin and thus inhibited transcription (17). The aim of the present study was to investigate the impact of promoter methylation and histone deacetylation of BIM in NSCLC cell lines and patients with NSCLC, to identify an association with EGFR-TKI resistance.

\section{Materials and methods}

Cell culture and in vitro treatment. A total of 8 human NSCLC cell lines were used in the present study. PC9, A549, H1299, H292,H1975 and H520 were obtained from the American Type Culture Collection (Manassas, VA, USA) and 2 gefitinib-resistant PC9 cell lines, PC9/R and PC9/G2, were induced in the laboratory. The culture methods for each cell line have been previously reported in multiple publications and were employed in the present study $(18,19)$. Cultured PC-9 cells were exposed to $2.5 \mu \mathrm{g} / \mathrm{ml} \mathrm{N}$-methyl-N'-nitro-N-nitrosoguanidine (MNNG) for $24 \mathrm{~h}$ and then washed and cultured in medium containing $0.2 \mu \mathrm{M}$ gefitinib for 7 days. Following exposure to gefitinib, cells were washed and cultured in drug-free medium for 14 days. When variable cells had grown, they were seeded in medium containing $0.3-0.5 \mu \mathrm{M}$ of gefitinib on 96-well cultured plates for subcloning. After 21-28 days, the colonies were harvested and a single clone was obtained. The subcloned cells exhibited an 182-fold increase in resistance to the growth-inhibitory effect of gefitinib as determined by MTT assay, and the resistant phenotype has been stable for at least 6 months under drug-free conditions. H520 cells were cultured in RPMI-1640 medium (Thermo Fisher Scientific, Inc., Waltham, MA, USA) and the remaining cell lines were cultured in Dulbecco's modified Eagle's medium (Thermo Fisher Scientific, Inc.), each supplemented with $10 \%$ fetal bovine serum (Gibco; Thermo Fisher Scientific, Inc.) and penicillin/streptomycin $(100 \mathrm{U} / \mathrm{ml})$. All cells were passaged within 3 months from their renewal from frozen or early-passage stocks. A commonly used de-methylating agent, 5-aza-2'-deoxycytidine (AZA; Sigma-Aldrich; Merck KGaA, Darmstadt, Germany) which inhibits DNA methyltransferase and Trichostatin A (TSA; Sigma-Aldrich; Merck KGaA), an HDAC inhibitor (HDACi) were used as cell culture supplements. All six cell lines (PC9, A549, H1299, H292, H1975 and H520) were respectively seeded at a density of $2 \times 10^{5}$ cells $/ \mathrm{cm}^{2}$
Table I. MI of tested cell lines by pyrosequencing and q-MSP.

\begin{tabular}{lccc}
\hline & \multicolumn{3}{c}{ MI (by pyrosequencing) } \\
\cline { 2 - 3 } Cell lines & $\begin{array}{c}\text { Position } 1 \\
(\%)\end{array}$ & $\begin{array}{c}\text { Position } 2 \\
(\%)\end{array}$ & $\begin{array}{c}\text { MI (by q-MSP) } \\
(\%)\end{array}$ \\
\hline PC9 & 2 & 4 & $6.22 \pm 0.16$ \\
PC9/R & 3 & 4 & $5.99 \pm 0.06$ \\
PC9/G2 & 3 & 3 & $10.85 \pm 0.56$ \\
H1299 & 6 & 6 & $16.59 \pm 0.93$ \\
H292 & 2 & 3 & $16.70 \pm 2.64$ \\
A549 & 3 & 4 & $15.52 \pm 1.37$ \\
H1975 & 8 & 5 & $15.21 \pm 1.25$ \\
H520 & 7 & 7 & $15.94 \pm 1.14$ \\
\hline
\end{tabular}

q-MSP, quantitative methylation specific polymerase chain reaction; MI, methylation index.

in 6- or 12-well plates and treated with the following reagents prior to further procedures. Group A cells were treated with $4 \mu \mathrm{m}$ AZA or $0.01 \mu \mathrm{m}$ DMSO for $96 \mathrm{~h}$, then $3 \mu \mathrm{m}$ gefitinib or continued 0.01 $\mu \mathrm{m}$ DMSO (Meilun, Dalian, Liaoning, China) for $72 \mathrm{~h}$. Therefore, four subgroups were produced: Negative control, which received DMSO twice, gefitinib group, received only gefitinib treatment, AZA group, which only received AZA and a combination group, received AZA and subsequently geftinib treatment. Group B cells received $0.02 \mu \mathrm{m}$ TSA or $0.01 \mu \mathrm{m}$ DMSO treatment for $16 \mathrm{~h}$, followed by $72 \mathrm{~h}$ of $3 \mu \mathrm{m}$ gefitinib or continued $0.01 \mu \mathrm{m}$ DMSO, generating four similar subgroups as aforementioned.

Reverse transcription quantitative-polymerase chain reaction (RT-qPCR.) BIM RNA expression levels were quantified by RT-qPCR. PC9, PC9/R, and PC9/G2 cell lines were randomly assigned into groups $\mathrm{A}$ and $\mathrm{B}$ and treated as aforementioned. Total RNA was extracted using an RNAiso Plus kit (Takara, Bio, Inc., Otsu, Japan) according to the manufacturer's protocol. Reverse transcription was performed with $1 \mu \mathrm{g}$ total RNA using the RevertAid First Strand cDNA Synthesis kit (Fermentas; Thermo Fisher Scientific, Inc.) according to the manufacturer's protocol. Gene quantification was analyzed by qPCR, run with $2 \mu \mathrm{l}$ cDNA and SYBR Premix Ex Taq (Takara, Bio, Inc.), on an Mx3000P qPCR system (Agilent Technologies, Santa Clara, CA, USA). GAPDH was used as the reference gene. The primer sequences were as follows: Bim forward, 5'-AGTGGGTATTTCTCTTTTGAC ACAG-3' and reverse: 5'-TCAATGCCTTCTCCATACCAG ACG-3'; GAPDH forward, 5'-TCGACAGTCAGCCGCATC TTCTTT-3' and reverse, 5'-ACCAAATCCGTTGACTCC GACCTT-3'. The reaction conditions were as follows: $94^{\circ} \mathrm{C}$ for $30 \mathrm{sec}$, followed by 40 cycles of $95^{\circ} \mathrm{C}$ for $5 \mathrm{sec}, 62^{\circ} \mathrm{C}$ for $20 \mathrm{sec}$, with a final extension of $72^{\circ} \mathrm{C}$ for $10 \mathrm{~min}$. Gene quantification was performed by automatic calculation using LightCycler software (version 1.5; Roche Applied Science, Penzberg, Germany) and BIM expression in the PC9 cell line was considered the base line, as this was the only cell line harboring activated EGFR mutations. 
A

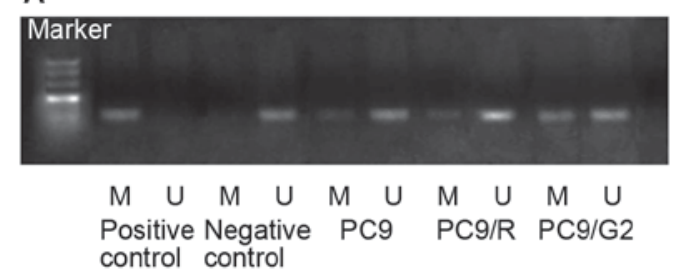

C

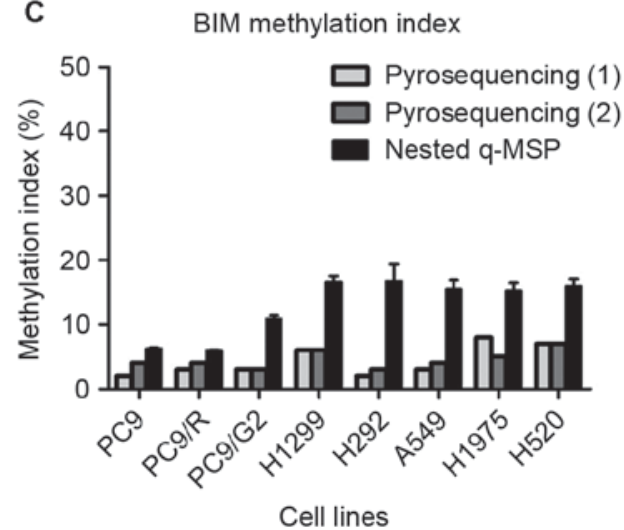

Cell lines
B
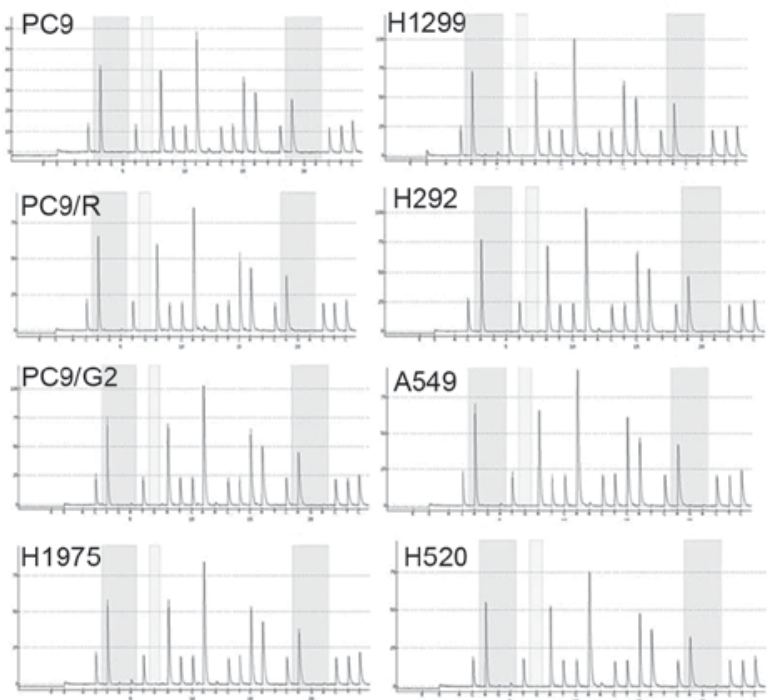

Figure 1. BIM promoter methylation analysis. (A) MSP analysis of the BIM promoter in the PC9 cell lines. PC9 and its two derivative, gefitinib resistant cell lines all presented with hypo-methylated BIM. (B) Pyrosequencing analysis of all studied cell lines. Blue regions mark the analyzed positions. (C) Comparison of the BIM methylation index by pyrosequencing and nested q-MSP in all studied cell lines. BIM, bcl-2-like protein 11; MSP, methylation specific polymerase chain reaction; q-, quantitative; $\mathrm{M}$, methylated; $\mathrm{U}$, unmethylated.

Cell cytotoxicity assay. Cells were seeded at a density of 4,000 cells/well in 96-well plates and treated as aforementioned prior to performing the cytotoxicity assay. Cells in each well were incubated with $100 \mu \mathrm{l}$ medium and $10 \mu \mathrm{l}$ Cell Counting Kit-8 reagent (CCK-8; Dojindo Molecular Technologies, Inc., Kumamoto, Japan) at $37^{\circ} \mathrm{C}$ for $1 \mathrm{~h}$. Following this, the absorbance was measured at $450 \mathrm{~nm}$ using a microplate reader. Data were calculated as the percentage of the total absorbance of treated cells/absorbance of non-treated cells and were expressed as the mean \pm standard error of the mean.

Methylation analysis. DNA was extracted from every cell line using DNeasy Blood \& Tissue kit or QIAamp DNA FFPE Tissue kit (Qiagen GmbH, Hilden, Germany) according to the manufacturer's protocol. A total of $500 \mathrm{ng}$ extracted cell line or plasma DNA was converted and purified using an EZ DNA Methylation-Gold kit (Zymo Research, Corp., Irvine, CA, USA), according to the manufacturer's protocol. The EpiTect PCR Control DNA set (Qiagen, Inc., Valencia, CA, USA) was used for methylated and unmethylated controls. Bisulfite converted DNA was analyzed by Methylation-Specific PCR (MSP), nested quantitative methylation specific PCR (nested q-MSP), and direct bisulfite pyrosequencing. For MSP, PCR amplification was performed in a total volume of $25 \mu \mathrm{l}$ with an ExTaq Polymerase premix PCR kit (Takara, Bio, Inc.), according to the manufacturer's protocol. Primer sequences for methylated and unmethylated $B I M$ promoters from the research of Eneriz et al (12) were used. Reaction conditions were as follows: $95^{\circ} \mathrm{C}$ for $10 \mathrm{~min}$, followed by 30 cycles of $94^{\circ} \mathrm{C}$ for $30 \mathrm{sec}, 60^{\circ} \mathrm{C}$ for $30 \mathrm{sec}, 72^{\circ} \mathrm{C}$ for $60 \mathrm{sec}$, and a final extension of $72^{\circ} \mathrm{C}$ for $10 \mathrm{~min}$. PCR products were then separated by electrophoresis on $3 \%$ agarose gel with ethidium bromide dye.
Nested $q$-MSP. DNA samples were amplified twice as in the aforementioned MSP protocol to amplify the signal and acquire the second round $\mathrm{Cq}$ value. The EpiTect PCR Control DNA Set was used to generate a standard curve to correct the different amplification efficacy of methylated and unmethylated promoters. Bisulfite converted DNA samples were subjected to the same protocol as control DNA mix, and the methylation index $(\mathrm{MI})$ was calculated with the following formula: $\mathrm{MI}=\mathrm{M} /(\mathrm{M}+\mathrm{U})=1 /[1+(\mathrm{U} / \mathrm{M})]=1 /\left(1+2^{\mathrm{CtM}-\mathrm{CtU}}\right)$.

Direct pyrosequencing. A total of 50 ng converted DNA was amplified using the PyroMark PCR kit (Qiagen GmbH, Hilden, Germany) and the reaction conditions were $95^{\circ} \mathrm{C}$ for $15 \mathrm{~min}$, followed by 45 cycles of $94^{\circ} \mathrm{C}$ for $30 \mathrm{sec}, 56^{\circ} \mathrm{C}$ for $30 \mathrm{sec}, 72^{\circ} \mathrm{C}$ for $60 \mathrm{sec}$, and a final extension of $72^{\circ} \mathrm{C}$ for $10 \mathrm{~min}$. The primers used for pyrosequencing were: Forward primer, 5'-ATAATG GGGTAGGAGTAGGGAA-3' and reverse primer, 5'-ATACTC TTTACCCAAAACAAACTT-3'. The specific PCR products were subjected to quantitative pyrosequencing analysis using a Biotage PyroMark Q96 system (Qiagen $\mathrm{GmbH}$ ) according to the manufacturer's protocol. The results were analyzed using Pyro Q-CpG 1.0.9 software (Qiagen $\mathrm{GmbH}$ ).

Patient details and EGFR-TKI treatment. This section of the present study was conducted retrospectively. Eligible patients were recruited if the following criteria were met: NSCLC histologically confirmed; received EGFR mutation status analysis; received EGFR-TKI therapy and regular follow up. A total of 32 patients were consecutively identified from the Shanghai Pulmonary Hospital (Shanghai, China) database according to the aforementioned criteria, from November 2011 to September 2012. Patients gave written informed consent for the scientific use of blood samples upon 
A

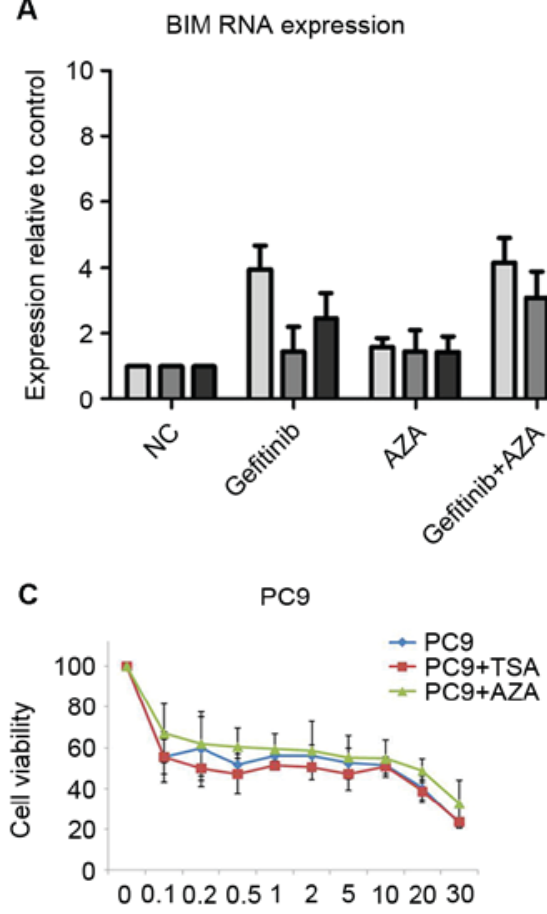

B

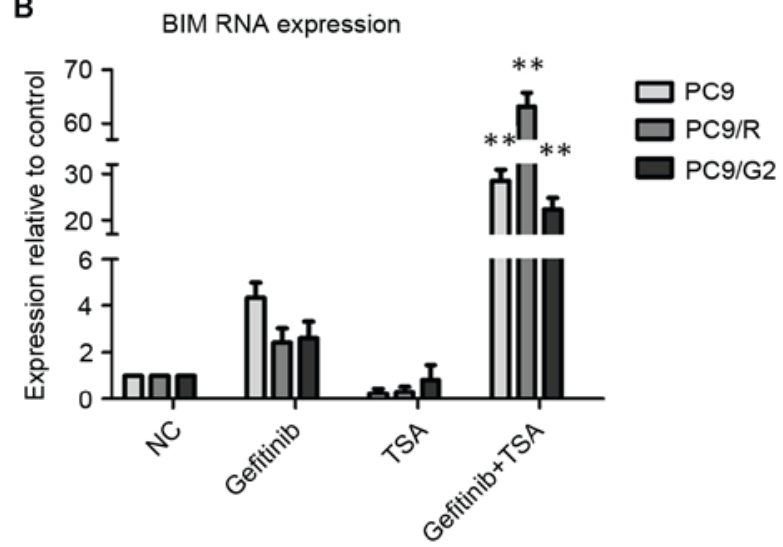

D

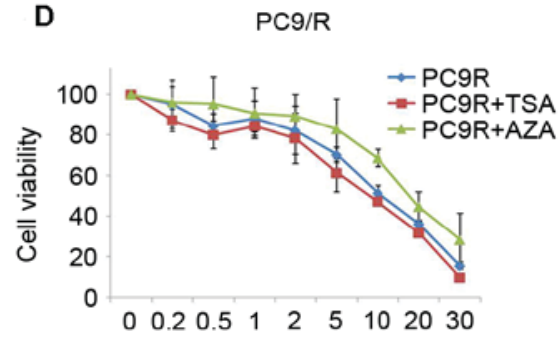

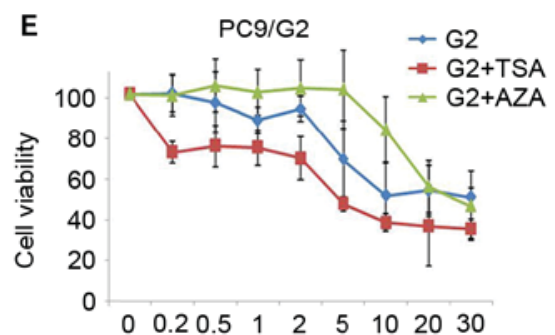

E
$\mathbf{F}$

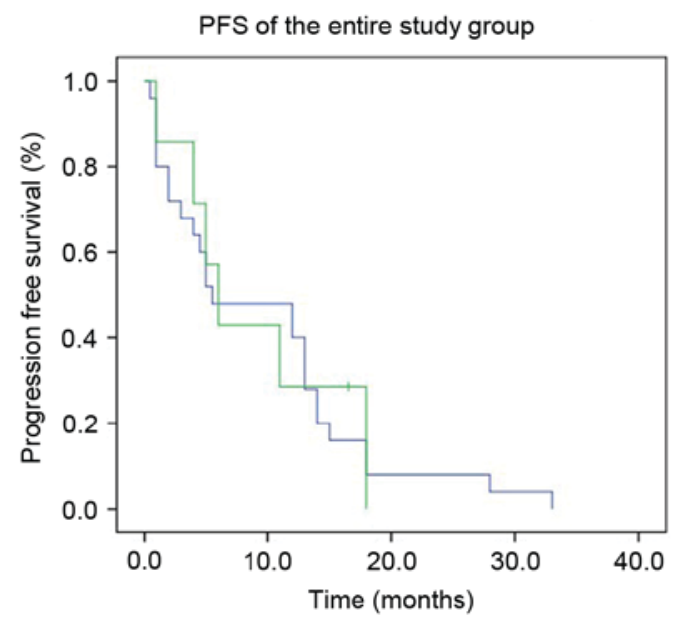

G

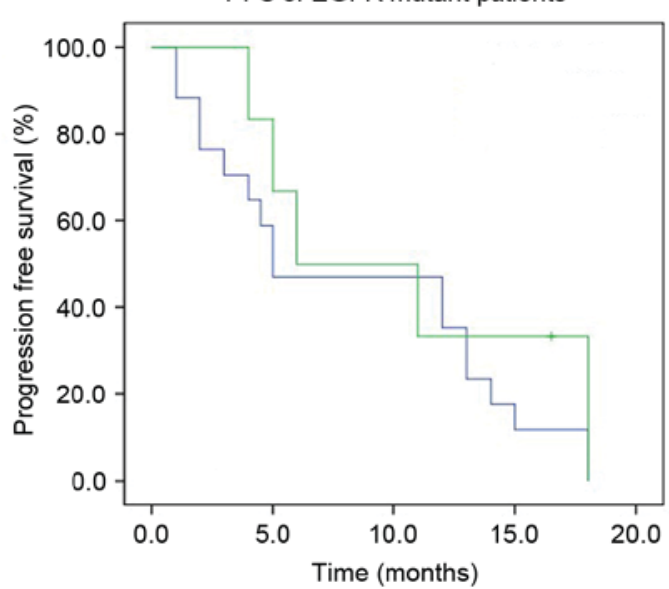

Mlgroup

$\neg$ hypo

$\neg$ Partial

Figure 2. In vitro assays. BIM gene expression levels in PC-9 cell lines following (A) AZA or (B) TSA treatments. Analysis of (C) PC9, (D) PC9/R and (E) PC9/G2 cell viability, following pre-treatments with TSA or AZA prior to gefitinib treatment. Cells pre-treated with TSA demonstrated lower tolerance to gefitinib compared with those that received gefitinib treatment alone. AZA pre-treatment, however, resulted in higher cell line resistance. Progression free survival curves of (F) the entire study group and (G) EGFR mutant groups. ${ }^{* *} \mathrm{P}<0.01$ vs. cells treated with DMSO and gefitinib. BIM, bcl-2-like protein 11 ; AZA, 5-Aza-2'-deoxycytidine; TSA, Trichostatin A; EGFR, epidermal growth factor receptor; PFS, progression free survival; NC, negative control.

the first occasion of hospitalization. A complete medical history interview, p hysical examination, laboratory test and radiology examination were performed for each case prior to starting treatment. All patients received $250 \mathrm{mg}$ gefitinib (Astrazeneca, Cambridge, UK) or $150 \mathrm{mg}$ erlotinib (Roche Applied Science, Penzberg, Germany) daily until disease progression or the appropriate toxic effect was observed. Tumor response was evaluated every 6 weeks according to the Response Evaluation Criteria in Solid Tumors (RECIST) version 1.1 (20), and progression free survival was the primary endpoint of the present study.

The present study was approved by the Ethics Committee of Shanghai Pulmonary Hospital Affiliated to Tongji University (Shanghai, China) and was performed in accordance with the
World Medical Association's Declaration of Helsinki. Written informed consent was obtained from each patient prior to initiation of any study-associated procedure.

Statistical analysis. All analyses were carried out using PASW 18.0 (SPSS Statistics; IBM Corp., Armonk, NY, USA). Statistical analyses were conducted using one-way analysis of variance to determine statistical significance between RNA expression levels groups in the in vitro studies and Bonferroni method was adopted as post-hoc test. The Kaplan-Meier method was used to plot the PFS curves and a log-rank test was used to compare the differences between groups in clinical data. $\chi^{2}$ test was used to determine the difference in the BIM methylation distribution pattern in the 
Table II. Clinical characteristics and MI distribution of patients with NSCLC with a median age of 56 (range, 32-78).

\begin{tabular}{|c|c|c|c|c|}
\hline \multirow{2}{*}{$\begin{array}{l}\text { Clinicopathological } \\
\text { characteristics }\end{array}$} & \multirow[b]{2}{*}{ Case $(\%)$} & \multicolumn{2}{|c|}{ MI } & \multirow[b]{2}{*}{ P-value } \\
\hline & & M & $\mathrm{N}$ & \\
\hline Sex & & & & 0.96 \\
\hline Male & $14(43.8)$ & 3 & 11 & \\
\hline Female & $18(56.3)$ & 4 & 14 & \\
\hline Smoking status & & & & 0.98 \\
\hline Smoker & $9(28.1)$ & 5 & 18 & \\
\hline Non-smoker & $23(71.9)$ & 2 & 7 & \\
\hline PS & & & & 0.96 \\
\hline 1 & $18(56.3)$ & 4 & 14 & \\
\hline 2 & $14(43.8)$ & 3 & 11 & \\
\hline Histological cell type & & & & $0.80^{\mathrm{a}}$ \\
\hline Adenocarcinoma & $24(75)$ & 5 & 19 & \\
\hline Squamous cell & $3(9.4)$ & 1 & 2 & \\
\hline Adenosquamocarcinoma & $2(6.3)$ & 0 & 2 & \\
\hline Others $^{\mathrm{b}}$ & $3(9.4)$ & 1 & 2 & \\
\hline EGFR status & & & & $0.23^{c}$ \\
\hline Wild type & $9(28.1)$ & 3 & 6 & \\
\hline 19Del & $12(37.5)$ & 6 & 6 & \\
\hline L858R & $9(28.1)$ & 6 & 3 & \\
\hline Others & $2(6.3)$ & 1 & 1 & \\
\hline
\end{tabular}

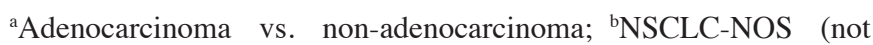

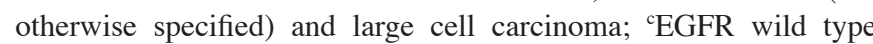
vs. EGFR mutant. MI, methylation index; PS, performance status; NSCLC, non-small cell lung carcinoma; EGFR, epidermal growth factor receptor; $\mathrm{M}$, methylated; $\mathrm{N}$, non-methylated.

baseline characteristics of patients. $\mathrm{P}<0.05$ was considered to indicate a statistically significant difference.

\section{Results}

BIM methylation status of NSCLC cell lines. The methylation status of the BIM promoter of PC9, PC9/R, and PC9/G2 cell lines using MSP was investigated (Fig. 1). PC9, PC9/R, and PC9/G2 cell lines all demonstrated hypo-methylation in BIM promoters. Pyrosequencing and nested q-MSP were used to further confirm the BIM promoter methylation status in the 8 cell lines. The $\mathrm{CpG}$ islands analyzed were selected based on the results from a previous study (12). The resulting methylation index (MI) of pyrosequencing is listed in Table I. According to a previous study on quantitative methylation analysis (12), DNA samples with $\mathrm{MI} \geq 50 \%$ were identified as hyper-methylated; those with $\mathrm{MI} \geq 20 \%$ were identified as partially methylated and $\mathrm{MI}<20 \%$ were considered hypo-methylated. Taken together, the results from MSP, pyrosequencing and nested q-MSP indicated that the hypo-methylated status of $B I M$ existed in all tested cell lines; including gefitinib sensitive PC9; gefitinib induced drug-resistance cell lines PC9/R and PC9/G2; EGFR TKI-primary resistance adenocarcinoma cell lines H292, A549, H1975; large-cell carcinoma H1299 and squamous carcinoma H520 (Table I and Fig. 1C). The two quantitative testing methods resulted in different methylation indexes. The divergence may reflect the difference between global and regional methylation status of the BIM promoter region.

BIM RNA expression level changes following treatment with $A Z A$ or TSA. In response to gefitinib treatment, two gefitinib resistant cell lines presented with reduced BIM mRNA levels compared with PC9 cells. Following AZA treatment, three cell lines demonstrated increased BIM transcript levels (Fig. 2A), although no significant differences were observed. Conversely, cell lines receiving TSA treatment demonstrated markedly elevated BIM mRNA levels compared with cells with no prior TSA stimulation $(\mathrm{P}<0.01$; Fig. $2 \mathrm{~B})$.

Cell cytotoxicity analysis. PC9, PC9/R and PC9/G2 cells were treated with the same treatment regime as described in the previous section. Following treatments, Cell Counting Kit- 8 (CCK-8) was utilized to test cell toxicity (Fig. 2C-E). In all three cell lines, cells pre-treated with TSA presented with a lower tolerance to gefitinib compared with cells that received gefitinib treatment alone. The effects of AZA pre-treatment, however, resulted in a higher resistance in all three tested cell lines.

Distribution of BIM methylation indexes in patients with NSCLC. The clinicopathological characteristics of the 32 patients with NSCLC recruited into the present study are listed in Table II. Amongst the 32 patients, the lowest methylated BIM index identified was 5.88, whilst the highest was 106.58. Patients were divided into three groups according to standards described in the 'BIM methylation status of NSCLC cell lines' section, and the subsequent associated data are listed in Table III. Patients with low BIM MI comprised the majority of the study group (78.1\%), whilst those with medium and high MI accounted for 15.6 and $6.3 \%$ of all patients, respectively. Data from the latter two groups were merged into one group (methylated group, group $\mathrm{M}$ ) in the following analysis due to the small identified sample size, and patients with low BIM were named the non-methylated group (group $\mathrm{N}$ ) in the subsequent analysis. The distribution between the $\mathrm{M}$ and $\mathrm{N}$ groups revealed no significant difference when assessed using a $\chi^{2}$ test assessing multiple clinicopathological characteristics, including gender $(\mathrm{P}=0.96)$, smoking status $(\mathrm{P}=0.98)$, performance status $(\mathrm{P}=0.96)$, histological type $(\mathrm{P}=0.80)$ and $\mathrm{EGFR}$ mutant status $(\mathrm{P}=0.24)$.

Analysis of BIM MI and EGFR TKI efficacy. All 32 patients received EGFR TKI, either gefitinib or erlotinib. By the cut-off point of the present study, none of the patients had stopped taking the medication due to intolerable toxicity prior to progression of the disease (PD). Of those patients, 31 (96.9\%) experienced PD, and 1 still had a stable disease (SD). The median PFS (mPFS) for the entire group was 5.75 months, with the shortest 0.5 months and longest 38 months. The EGFR TKI efficacy in the entire group and EGFR mutant subgroup with different BIM MI is listed in Table IV. In both the entire study population and EGFR mutant patients, PFS did not significantly differ between the $\mathrm{M}$ and $\mathrm{N}$ groups (Table IV, Fig. 2F-G). 
Table III. BIM promoter methylation status in patients with non small cell lung carcinoma.

\begin{tabular}{lccc}
\hline Variable & Hypo-methylated & Partially-methylated & Hyper-methylated \\
\hline Case $(\%)$ & $25(78.1)$ & $5(15.6)$ & $2(6.3)$ \\
Mean MI (\%) & 9.08 & 22.67 & 80.48 \\
$(95 \%$ CI) & $(7.32-10.84)$ & $(19.69-25.66)$ & $(-251.23-412.18)$ \\
Minimum-maximum MI (\%) & $5.88-18.11$ & $20.81-26.41$ & $54.37-106.58$ \\
Median MI (\%) & 6.32 & 21.17 & 80.48 \\
\hline
\end{tabular}

MI, methylation index; CI, confidence interval.

\section{Discussion}

The aim of the present study was to investigate the impact of BIM promoter methylation and histone deacetylation on EGFR TKI resistance. In all NSCLC cell lines examined, and samples from the majority of patients with NSCLC, BIM gene promoter regions were hypo-methylated. The demethylating agent, AZA, did not affect BIM mRNA expression in EGFR TKI-resistant cell lines. HDACi, TSA significantly increased BIM mRNA levels and reversed the TKI resistance of PC9/R and PC9/G2 cell lines.

Epigenetic BIM silencing has been previously reported to be associated with various malignancies $(12,13)$. Furthermore, abnormal methylation has been identified as a hallmark of cancer $(21,22)$. In previous years, the involvment of epigenetic regulation in the acquisition of drug resistance has been addressed due to development of cancer genome charts (23). In NSCLC, genes including multiple tumor suppressor 1 ( $p 16)$, adenomatous polyposis coli $(A P C)$ and death associated protein kinase 1 were proven to be hyper-methylated in the promoter region $(24,25)$.

In the present study, BIM was observed to be hypo-methylated in NSCLC, as evaluated by various methods, indicating the difference between NSCLC and hematological malignancies or renal carcinoma. Despite the heterogeneity in the tumorigenesis and development of NSCLC, due to the discrepancies observed, it was not possible to exclude epigenetic alteration of cell lines following in vitro culture. However, further exploratory research using circulating free DNA from patients with NSCLC confirmed that the hypo-methylated status of BIM was observed in the majority of patients (78.1\%). The collective in vitro and in vivo results suggested that BIM was hypo-methylated in the majority of NSCLC cases and that promoter methylation did not contribute to EGFR TKI resistance. Increased resistance to gefitinib following the AZA-induced treatment in PC9, PC9/R, and PC9/G2 cell lines revealed AZA's protection of cell lines from gefitinib. Such protection suggested that anti-apoptotic and/or cell cycle regulating genes may be switched on following AZA treatment, thereby rescuing epigenetic silencing.

The two PC9 gefitinib-resistant cell lines presented with impaired BIM mRNA expression, indicating that epigenetic factors may still regulate BIM. Thus, histone deacetylation, another epigenetic regulating mechanism associated with methylation, was further investigated. TSA pre-treatment led to a marked upregulation of BIM and gefitinib tolerance
Table IV. Efficacy of EGFR-tyrosine kinase inhibitor treatment in patients with non small cell lung cancer.

\begin{tabular}{lcc}
\hline Group & Median PFS $(95 \% \mathrm{CI})$ & \\
\hline & Study population & EGFR mutants \\
$\mathrm{N}$ & $5.500(0.000-12.844)$ & $5.000(0.000-12.563)$ \\
$\mathrm{M}$ & $6.000(3.434-8.566)$ & $6.000(0.000-13.201)$ \\
Total & $5.500(0.000-11.506)$ & $6.000(0.000-12.104)$ \\
\hline
\end{tabular}

$\mathrm{N}$, hypo-methylated BIM; M, partial- and hyper-methylated BIM; EGFR, epidermal growth factor receptor.

reduction in PC9 gefitinib-resistant cell lines, indicating that histone deacetylation, as opposed to methylation may be involved in the epigenetic BIM silencing. Another HDACi, verinostat, has been demonstrated to increase BIM expression in EGFR mutant NSCLC cell lines, harboring either wild type or deletion polymorphism BIM under TKI treatment (26). However, BIM methylation and histone deacetylation status were not directly detected in the aforementioned study. A previous study conducted on Burkitt lymphoma revealed the co-existence of promoter methylation and histone deacetylation of BIM in cell lines; and demonstrated that verinostat was able to reverse chemotherapy resistance by overcoming epigenetic silencing (13). However, in a clinical trial comparing erlotinib, with or without HDACi entinostat in patients with advanced stage NSCLC (27), the combined regime did not prove to be beneficial, which may highlight the importance of patient selection. Another previous study analyzed the single and combined effects of AZA and TSA on a multi-drug resistant cell line, and demonstrated that the anti-resistant effect of each single drug is not additive but interactive (28), offering a new viewpoint for our follow-up study on the investigation of combined AZA and TSA to treat NSCLC.

To the best of our knowledge, the present study is the first to use a quantitative method to analyze methylation status using circulating free DNA (cfDNA). Over previous decades, researchers have identified the existence of cfDNA $(29,30)$. Tumor-specific changes including point mutation, DNA methylation, and microsatellite instability revealed that these cfDNAs originated from tumors $(31,32)$. Since peripheral blood is considerably easier to acquire compared with tissue samples, the use of cfDNA may be beneficial to detect and/or monitor the methylation profile of genes of interest. Multiple 
studies have been conducted which detect methylation using cfDNA, including APC, RAS, and the Ras association domain family $1 \mathrm{~A}$ gene in ovarian cancer (33); tumor suppressor gene BLU, Cadherin 13, fragile histidine triad and p16 in lung cancer (34). MSP, which provides qualitative results, is a commonly used method in such studies, and the incidence of methylated DNA detected in serum is commonly reduced compared with that in tumor tissue. In the present study, the aim was to combine nested PCR with quantitative MSP in order to acquire precise methylation information, using cfDNA.

In the present study, the small proportion $(6.3 \%)$ of patients with hyper-methylated BIM indicated that patients with NSCLC often present with hypo-methylated BIM. These observations are consistent with the results presented from the in vitro study cell lines. PFS analyses revealed that no significant differences were observed between the $\mathrm{M}$ and $\mathrm{N}$ patient groups in the entire study group $(\mathrm{P}=0.859)$ and EGFR mutant subgroup $(\mathrm{P}=0.395)$; indicating that there was no existing association between BIM methylation and EGFR TKI efficacy in patients with NSCLC. There are several potential explanations for the results presented here. As previously stated, BIM methylation status may not influence EGFR TKI efficacy in patients with NSCLC. In addition, the BIM methylation index detected in cfDNA may not reflect the in vivo tumor tissue status, since the phenomenon of methylated DNA detected in serum was reduced compared with that in tumor tissue, which was also observed in several previous studies $(25,33,34)$. Furthermore, although the present study was exploratory, the population size was small and the test efficiency weak. Hence, a paired study comparing methylation profiles in cfDNA and tissue with increased case numbers may reflect the function of $B I M$ methylation in NSCLC target therapy more accurately.

In conclusion, the present study detected the BIM methylation profile in NSCLC cell lines and patients with NSCLC, and the cell lines and patients collectively presented with hypo-methylated BIM. The histone deacetylation inhibitor, TSA, but not the methylation inhibitor, AZA, reversed the resistance to EGFR TKI in acquired resistance cell lines PC9/R and PC9/G2. Thus, histone deacetylation as opposed to promoter methylation, may contribute in the epigenetic silencing of BIM and lead to EGFR-TKI resistance in NSCLC.

\section{Acknowledgements}

The authors would like to thank Amoy Diagnostics Company, Ltd., for technical support. The abstract was presented at Annual Meeting of The European Society for Medical Oncology, September 27th 2014 in Madrid, Spain and published as abstract no. 1320P in Annals of Oncology 25 (supplement 4): 2014.

\section{References}

1. Jemal A, Bray F, Center MM, Ferlay J, Ward E and Forman D: Global cancer statistics. CA Cancer J Clin 61: 69-90, 2011.

2. Ferlay J, Shin HR, Bray F, Forman D, Mathers C and Parkin DM: Estimates of worldwide burden of cancer in 2008: GLOBOCAN 2008. Int J Cancer 127: 2893-2917, 2010.

3. Rosell R, Moran T, Queralt C, Porta R, Cardenal F, Camps C, Majem M, Lopez-Vivanco G, Isla D, Provencio M, et al: Screening for epidermal growth factor receptor mutations in lung cancer. N Engl J Med 361: 958-967, 2009.
4. Giaccone G, Gallegos Ruiz M, Le Chevalier T, Thatcher N, Smit E, Rodriguez JA, Janne P, Oulid-Aissa D and Soria JC: Erlotinib for frontline treatment of advanced non-small cell lung cancer: A phase II study. Clin Cancer Res 12: 6049-6055, 2006.

5. Zhou C, Wu YL, Chen G, Feng J, Liu XQ, Wang C, Zhang S, Wang J, Zhou S, Ren S, et al: Erlotinib versus chemotherapy as first-line treatment for patients with advanced EGFR mutation-positive non-small-cell lung cancer (OPTIMAL, CTONG-0802): A multicentre, open-label, randomised, phase 3 study. Lancet Oncol 12: 735-742, 2011.

6. Kobayashi S, Boggon TJ, Dayaram T, Jänne PA, Kocher O, Meyerson M, Johnson BE, Eck MJ, Tenen DG and Halmos B: EGFR mutation and resistance of non-small-cell lung cancer to gefitinib. N Engl J Med 352: 786-792, 2005.

7. Nakazawa Y, Saha S, Galvan DL, Huye L, Rollins L, Rooney CM and Wilson MH: Evaluation of long-term transgene expression in piggyBac-modified human $\mathrm{T}$ lymphocytes. J Immunother 36 : 3-10, 2013.

8. Riely GJ, Kris MG, Zhao B, Akhurst T, Milton DT, Moore E, Tyson L, Pao W, Rizvi NA, Schwartz LH and Miller VA: Prospective assessment of discontinuation and reinitiation of erlotinib or gefitinib in patients with acquired resistance to erlotinib or gefitinib followed by the addition of everolimus. Clin Cancer Res 13: 5150-5155, 2007.

9. Ng KP, Hillmer AM, Chuah CT, Juan WC, Ko TK, Teo AS, Ariyaratne PN, Takahashi N, Sawada K, Fei Y, et al: A common BIM deletion polymorphism mediates intrinsic resistance and inferior responses to tyrosine kinase inhibitors in cancer. Nat Med 18: 521-528, 2012.

10. Zhao M, Zhang Y, Cai W, Li J, Zhou F, Cheng N, Ren R, Zhao C, Li X, Ren S, et al: The Bim deletion polymorphism clinical profile and its relation with tyrosine kinase inhibitor resistance in Chinese patients with non-small cell lung cancer. Cancer 120: 2299-2307, 2014.

11. O'Connor L, Strasser A, O'Reilly LA, Hausmann G, Adams JM, Cory $\mathrm{S}$ and Huang DC: Bim: A novel member of the Bcl-2 family that promotes apoptosis. EMBO J 17: 384-395, 1998.

12. San José-Eneriz E, Agirre X, Jiménez-Velasco A, Cordeu L, Martín V, Arqueros V, Gárate L, Fresquet V, Cervantes F, Martínez-Climent JA, et al: Epigenetic down-regulation of BIM expression is associated with reduced optimal responses to imatinib treatment in chronic myeloid leukaemia. Eur J Cancer 45: 1877-1889, 2009.

13. Richter-Larrea JA, Robles EF, Fresquet V, Beltran E, Rullan AJ, Agirre X, Calasanz MJ, Panizo C, Richter JA, Hernandez JM, et al: Reversion of epigenetically mediated BIM silencing overcomes chemoresistance in Burkitt lymphoma. Blood 116: 2531-2542, 2010.

14. Piazza R, Magistroni V, Mogavero A, Andreoni F, Ambrogio C Chiarle R, Mologni L, Bachmann PS, Lock RB, Collini P, et al: Epigenetic silencing of the proapoptotic gene BIM in anaplastic large cell lymphoma through an MeCP2/SIN3a deacetylating complex. Neoplasia 15: 511-522, 2013.

15. Zantl N, Weirich G, Zall H, Seiffert BM, Fischer SF, Kirschnek S, Hartmann C, Fritsch RM, Gillissen B, Daniel PT and Häcker G: Frequent loss of expression of the pro-apoptotic protein Bim in renal cell carcinoma: Evidence for contribution to apoptosis resistance. Oncogene 26: 7038-7048, 2007.

16. Singal R and Ginder GD: DNA methylation. Blood 93: 4059-4070, 1999.

17. Fuks F, Burgers WA, Brehm A, Hughes-Davies L and Kouzarides T: DNA methyltransferase Dnmt1 associates with histone deacetylase activity. Nat Genet 24: 88-91, 2000.

18. Ju L, Zhou C, Li W and Yan L: Integrin betal over-expression associates with resistance to tyrosine kinase inhibitor gefitinib in non-small cell lung cancer. J Cell Biochem 111: 1565-1574, 2010.

19. Li B, Ren S, Li X, Wang Y, Garfield D, Zhou S, Chen X, Su C, Chen M, Kuang P, et al: MiR-21 overexpression is associated with acquired resistance of EGFR-TKI in non-small cell lung cancer. Lung Cancer 83: 146-153, 2014.

20. Eisenhauer EA, Therasse P, Bogaerts J, Schwartz LH, Sargent D, Ford R, Dancey J, Arbuck S, Gwyther S, Mooney M, et al: New response evaluation criteria in solid tumours: Revised RECIST guideline (version 1.1). Eur J Cancer 45: 228-247, 2009.

21. Toyooka S, Toyooka KO, Maruyama R, Virmani AK, Girard L, Miyajima K, Harada K, Ariyoshi Y, Takahashi T, Sugio K, et al: DNA methylation profiles of lung tumors. Mol Cancer Ther 1: $61-67,2001$. 
22. Zöchbauer-Müller S, Fong KM, Virmani AK, Geradts J, Gazdar AF and Minna JD: Aberrant promoter methylation of multiple genes in non-small cell lung cancers. Cancer Res 61: 249-255, 2001.

23. Wilting RH and Dannenberg JH: Epigenetic mechanisms in tumorigenesis, tumor cell heterogeneity and drug resistance. Drug Resist Updat 15: 21-38, 2012.

24. Yang Y, Takeuchi S, Hofmann WK, Ikezoe T, van Dongen JJ, Szczepański T, Bartram CR, Yoshino N, Taguchi H and Koeffler HP: Aberrant methylation in promoter-associated $\mathrm{CpG}$ islands of multiple genes in acute lymphoblastic leukemia. Leuk Res 30: 98-102, 2006.

25. Fujiwara K, Fujimoto N, Tabata M, Nishii K, Matsuo K, Hotta K, Kozuki T, Aoe M, Kiura K, Ueoka H and Tanimoto M: Identification of epigenetic aberrant promoter methylation in serum DNA is useful for early detection of lung cancer. Clin Cancer Res 11: 1219-1257, 2005.

26. Nakagawa T, Takeuchi S, Yamada T, Ebi H, Sano T, Nanjo S, Ishikawa D, Sato M, Hasegawa Y, Sekido Y and Yano S: EGFR-TKI resistance due to BIM polymorphism can be circumvented in combination with HDAC inhibition. Cancer Res 73 2428-2434, 2013.

27. Witta SE, Jotte RM, Konduri K, Neubauer MA, Spira AI, Ruxer RL, Varella-Garcia M, Bunn PA Jr and Hirsch FR: Randomized phase II trial of erlotinib with and without entinostat in patients with advanced non-small-cell lung cancer who progressed on prior chemotherapy. J Clin Oncol 30: 2248-2255, 2012 .
28. Capobianco E, Mora A, La Sala D, Roberti A, Zaki N, Badidi E, Taranta $M$ and Cinti C: Separate and combined effects of DNMT and HDAC inhibitors in treating human multi-drug resistant osteosarcoma HosDXR150 cell line. PLoS One 9: e95596, 2014.

29. Leon SA, Shapiro B, Sklaroff DM and Yaros MJ: Free DNA in the serum of cancer patients and the effect of therapy. Cancer Res 37: 646-650, 1977.

30. Stroun M, Anker P, Maurice P, Lyautey J, Lederrey C and Beljanski M: Neoplastic characteristics of the DNA found in the plasma of cancer patients. Oncology 46: 318-322, 1989.

31. Nawroz H, Koch W, Anker P, Stroun M and Sidransky D: Microsatellite alterations in serum DNA of head and neck cancer patients. Nat Med 2: 1035-1037, 1996.

32. Mulcahy HE, Lyautey J, Lederrey C, qi Chen X, Anker P, Alstead EM, Ballinger A, Farthing MJ and Stroun M: A prospective study of K-ras mutations in the plasma of pancreatic cancer patients. Clin Cancer Res 4: 271-275, 1998.

33. Ibanez de Caceres I, Battagli C, Esteller M, Herman JG, Dulaimi E, Edelson MI, Bergman C, Ehya H, Eisenberg BL and Cairns P: Tumor Cell-Specific BRCA1 and RASSF1A Hypermethylation in Serum, Plasma, and Peritoneal Fluid from Ovarian Cancer Patients. Cancer Res 64: 6476-6481, 2004.

34. Hsu HS, Chen TP, Hung CH, Wen CK, Lin RK, Lee HC and Wang YC: Characterization of a multiple epigenetic marker panel for lung cancer detection and risk assessment in plasma. Cancer 110: 2019-2026, 2007. 